\title{
Enduring behavioral effects of weaning-through-puberty cocaine dosing in the rat
}

\author{
ROBERT F. SMITH, C. NANI MEDICI, and DANI K. RAAP \\ George Mason University, Fairfax, Virginia
}

\begin{abstract}
To determine whether cocaine administration during a developmental period corresponding to middle and late childhood results in enduring changes in behavior, we injected rats with 5 or $20 \mathrm{mg} / \mathrm{kg} / \mathrm{d} \mathrm{of} \mathrm{co-}$ caine s.c. from weaning (postnatal day 21; P21) through P60; controls included uninjected and vehicleinjected controls. The $20-\mathrm{mg} / \mathrm{kg}$ dose resulted in a transient, male-limited weight reduction for the last 10 days of dosing, which rapidly recovered to normal after dosing ceased. Approximately 5 months later, the subjects were given a brief battery of behavioral tests. Female 20 -mg subjects received fewer reinforcements than control subjects in a DRL-20 task. Female subjects also displayed altered patterns of cocaine-stimulated changes in open-field activity. No significant lasting effects were seen in males. These data suggest that the central nervous system retains sufficient plasticity into later development to produce long-lasting functional changes in response to drug administration and that cocaine consumption during the rat equivalent of childhood produces very long lasting plastic changes in behavior.
\end{abstract}

Developmental exposure to a number of drugs, including alcohol (Driscoll, Streissguth, \& Riley, 1990), opiates (Kaltenbach \& Finnegan, 1989), and cocaine (Chasnoff, Burns, Schnoll, \& Burns, 1985; Smith, Mattran, Kurkjian, \& Kurtz, 1989) has been investigated. For cocaine, most developmental studies in animals have focused on the effects of administration during the prenatal period. A few have included administration on postnatal days 1-10 (P1-P10; see, e.g., Barron \& Irvine, 1994) or P11-20 (Dow-Edwards, Fried-Malen, \& Hughes, 1993). Although many effects are not of large magnitude, developmental cocaine has been reported to produce effects on behavior (Heyser, Chen, Miller, Spear, \& Spear, 1990; Johns, Means, Anderson, Means, \& McMillen, 1992; Smith et al., 1989; Spear, Kirstein, \& Frambes, 1989), cerebral metabolic rates (Dow-Edwards, Fried, \& Fico, 1990; Dow-Edwards et al., 1993), and many physiological systems (Akbari, Kramer, Whittaker-Azmitia, Spear, \& Azmitia, 1992; Goodwin, Moody, \& Spear, 1993; Raum, McGivern, Peterson, Shryne, \& Gorski, 1990; Smith, Royall, \& Coss, 1995; Vathy, Katay, \& Mini, 1993), as measured later in life.

In humans, exposure to cocaine during childhood and adolescence has been documented (e.g., Hicks, Morales, \& Soldin, 1990; U.S. Department of Health and Human Services, 1991). Although lasting effects of cocaine administration as late as P11-20 have been reported in animal studies (Dow-Edwards et al., 1993), no studies to date

C.N.M. and D.K.R. were supported by George Mason University Graduate Research Assistantships. Cocaine was supplied by the NIDA Drug Supply System. We thank Elizabeth A. McVay, Joseph Adinaro, Lori Kent, and Alan Schwalb for assistance with data collection. Correspondence concerning this article should be addressed to R. F. Smith, Department of Psychology, George Mason University, Fairfax, VA 22030 (e-mail: bsmith@gmu.edu). have investigated possible lasting effects of cocaine administered during a period corresponding to human childhood and early adolescence. The central nervous system (CNS) retains developmental plasticity during this period, however; many reports indicate that a well-studied manipulation, environmental enrichment, produces changes in fine neuromorphology (e.g., Greenough, 1987), especially of systems developing at the time of enrichment (Fernandez, Adaro, Sanhueza-Tsusumi, Inzunza, \& Bravo, 1997). This continued plasticity is part of the rationale for Witt's (1994) recommendation of assessing an animal model of adolescent use of another addictive drug, alcohol. The present study was conducted as a preliminary assessment of whether pre- and periadolescent [PPA] cocaine usage in the rat induces lasting changes in behavior. We selected P21-P60 as dosing ages for two reasons: (1) It incorporates an age range previously uninvestigated, and (2) this work was intended to serve as a model for cocaine use in PPA children. Although it is difficult to establish exact age equivalencies between rats and humans, this time period begins 6-7 days before clear prepubertal changes in females and persists past sexual maturity in both males and females. Doses included a low dose $(5 \mathrm{mg} / \mathrm{kg})$ and a moderate dose $(20 \mathrm{mg} / \mathrm{kg}$, about $0.3 \mathrm{LD} 50$ for adult rats), as well as uninjected and vehicleinjected controls.

\section{METHOD}

\section{Subjects}

Forty ( 20 male and 20 female) Long-Evans hooded rats (LSD:blu) used as subjects were derived from litters bred in our laboratory and culled to 4 males and 4 females on the day of birth. Animals were weaned on the 1 st day of administration and were housed individually in hanging wire cages. The subjects had ad-lib access to water and food, except when food deprivation was required for differential reinforcement of low rates of responding (DRL-20) testing. The 
animals were maintained on a 12:12-h light:dark schedule (0700$1900 \mathrm{on}$ ), in a colony maintained at $20-25.5^{\circ} \mathrm{C}$. Cocaine injection occurred from $0900-1100$, and behavioral testing from $1000-1700$.

\section{Drug Administration}

Dose groups included 5 and $20 \mathrm{mg} / \mathrm{kg} / \mathrm{d}$ of cocaine, a vehicleinjected control group, and an uninjected control group. The subjects were injected daily from P21 through P60. Cocaine hydrochloride (NIDA Drug Supply System) was mixed daily as a $10-\mathrm{mg} / \mathrm{ml}$ solution in sterile isotonic saline. Side of subcutaneous injection (chosen for slow absorption and a relatively long duration of action) to the flank was altered daily, and location on each side was varied. Minor necrosis occurred at the injection sites in $20-\mathrm{mg} / \mathrm{kg}$ subjects. Body weights were taken daily during the administration period.

\section{Design}

The study was designed to control for genetic components of variance. From each of the five litters, one male and one female were assigned to the 5-mg dose group, one sex pair to the $20-\mathrm{mg}$ dose group, and one sex pair to each of the injected and uninjected control groups. No pairfed control was included, since previous work indicated that a reduction in food intake is not seen in pregnant females at doses as low as $20-\mathrm{mg} / \mathrm{kg}$ (e.g., Smith et al., 1989). Each animal was tested sequentially on each of the behavioral tests. Behavioral tests started at 215 days of age ( 155 days after dosing ended).

Open Field. Open field testing was chosen for its sensitivity both to cocaine administration earlier in life (see, e.g., Smith et al., 1989) and to juvenile manipulations such as enrichment (Morgan, 1973). A $76 \times 76 \mathrm{~cm}$ box with four BRS/LVE infrared photosensors (two in each horizontal dimension) was used to record motor activity. The OPN software system (Spencer \& Emmett-Oglesby, 1985), running on IBM PCs, segregated beam breaks into six consecutive 5 -min periods.

\section{DRL-20 Sec Acquisition}

DRL responding was used to assess the ability of the animals to learn to pattern responses appropriately to the schedule. As with the open field, both cocaine administration earlier in development (Smith et al., 1989), and juvenile manipulations such as enrichment (Ough, Beatty, \& Khalili, 1972) affect this measure. Gerbrands G7321 Skinner boxes were housed in BRS/LVE sound attenuation chambers and were controlled by the OPN software system. Beginning 5 days after open field testing, the subjects were food deprived to $80 \%$ of their ad-lib weight, shaped to barpress, and given 4 days of $30 \mathrm{~min}$ per day on a continuous reinforcement schedule. After pretraining, the subjects were shifted to a DRL-20-sec schedule for $30 \mathrm{~min}$ per day for 20 days.

\section{Cocaine-Stimulated Activity}

Five days after the completion of DRL training (and resumption of ad-lib feeding), the subjects were given an intraperitoneal injection of $5 \mathrm{mg} / \mathrm{kg}$ of cocaine $10 \mathrm{~min}$ prior to a 10 -min session in the open field, using the apparatus described above. The intraperitoneal route was chosen for relatively rapid absorption, producing high serum levels and strong effects on activity.

\section{Data Analysis}

Because of the design of the study, a subject in each dose/gender combination was a littermate of 1 subject in each of the other dose/ gender combinations. Since there are litter (genetic) contributions to some behaviors, the subjects within each gender/dose combination were not independent of the subjects in each other combination; their behavior was correlated by virtue of their genetic relationships. A traditional analysis of variance (ANOVA), treating dose and gender as between-subjects effects, would thus violate the assumption of independence of each data point. Thus, the analysis selected was to treat dose and gender as correlated measures in an ANOVA (see Kirk, 1982; Winer, 1971). Significant ANOVA effects were followed by Newman-Keuls post hoc tests.

\section{RESULTS}

An ANOVA of weekly body weights during cocaine administration indicated that there were significant drug $\times$ day $[F(12,138)=2.67, p<.01]$ and drug $\times$ sex $\times$ day $[F(12,138)=2.39, p<.01]$ interactions. As Table 1 indicates, 20-mg males, but not females, had reduced body weight gain from P50 through P60, as compared with saline-injected controls. At P60, 20-mg males weighed $7.3 \%$ less than control males. Following completion of administration, differences in body weights disappeared within 10 days (data not shown).

An ANOVA of activity counts during the 30 -min open field testing revealed no group-related differences, although expected time period $[F(5,20)=60.43, p<.001]$ and sex [sex $\times$ trial interaction; $F(5,20)=6.70, p<$ $.001]$ effects were observed. An ANOVA for the two 5min periods of activity following cocaine administration revealed no significant drug-associated effects, although the drug $\times$ sex $\times$ time periods effect approached significance $[F(3,12)=3.43, p<.06]$. To compare basal and cocaine-stimulated activity, an ANOVA was performed,

Table 1

Body Weights During Dosing

\begin{tabular}{|c|c|c|c|c|c|c|c|c|c|c|c|c|c|c|}
\hline \multirow[b]{3}{*}{ Dose Group } & \multicolumn{14}{|c|}{ Age (in Days) } \\
\hline & \multicolumn{2}{|c|}{21} & \multicolumn{2}{|c|}{28} & \multicolumn{2}{|c|}{35} & \multicolumn{2}{|c|}{42} & \multicolumn{2}{|c|}{49} & \multicolumn{2}{|c|}{56} & \multicolumn{2}{|l|}{60} \\
\hline & $M$ & $\overline{S E M}$ & $M$ & $S E M$ & $M$ & $S E M$ & $M$ & $\overline{S E M}$ & $M$ & $\overline{S E M}$ & $M$ & $\overline{S E M}$ & $M$ & $S E M$ \\
\hline \multicolumn{15}{|c|}{ Males } \\
\hline Saline & 46.8 & 1.34 & 78.7 & 1.93 & 133.2 & 2.02 & 185.0 & 2.85 & 239.6 & 1.21 & 290.7 & 2.04 & 316.6 & 4.04 \\
\hline 5 mg cocaine & 44.7 & 1.83 & 81.3 & 2.83 & 133.4 & 4.90 & 187.3 & 6.46 & 238.1 & 7.91 & 288.3 & 7.95 & 311.1 & 9.51 \\
\hline $20 \mathrm{mg}$ cocaine & 48.6 & 2.10 & 83.6 & 3.74 & 137.9 & 6.85 & 188.9 & 7.19 & 233.4 & 8.53 & $276.8^{*}$ & 8.98 & $294.0^{*}$ & 8.05 \\
\hline \multicolumn{15}{|c|}{ Females } \\
\hline Saline & 46.8 & 1.63 & 77.2 & 1.87 & 122.1 & 2.61 & 152.6 & 2.97 & 181.1 & 2.64 & 198.5 & 1.84 & 212.1 & 2.92 \\
\hline $5 \mathrm{mg}$ cocaine & 45.0 & 1.44 & 73.7 & 1.91 & 115.6 & 2.57 & 150.6 & 3.57 & 178.8 & 4.64 & 202.2 & 5.14 & 211.7 & 5.48 \\
\hline $20 \mathrm{mg}$ cocaine & 45.7 & 1.67 & 73.9 & 2.72 & 116.5 & 4.10 & 150.9 & 6.26 & 175.9 & 6.98 & 199.7 & 9.06 & 208.5 & 8.44 \\
\hline
\end{tabular}


comparing the two 5-min periods of cocaine-stimulated activity with the first two 5-min periods of basal activity. This ANOVA revealed a significant fourth-order interaction between periadolescent drug, gender, time period, and pretest cocaine dosing $[F(3,12)=4.27, p<.05$; see Figure 1]. Newman-Keuls post hoc tests failed to determine specific group differences contributing to this interaction; Figure 1, which depicts cocaine-stimulated activity as percent change from basal level, suggests that it is attributable to time-period-specific changes in cocainestimulated activity, limited to female subjects. Females who were uninjected during the PPA period have a large increase in activity in response to cocaine during the first 5 min of activity, but a negligible increase during the second period. The first-period increase is muted in animals dosed with cocaine during the PPA period (especially in the 5-mg group), but the second-period change is larger in 20-mg animals than in controls.

An ANOVA on reinforcements received during the 20 days of DRL testing indicated significant drug $\times$ day $[F(57,228)=2.52, p<.001]$, drug $\times \operatorname{sex}[F(3,12)=5.02$, $p<.05]$, and drug $\times$ sex $\times$ day $[F(57,228)=2.16, p<$ $.001]$ interactions. These were principally attributable to female 20 -mg animals receiving fewer reinforcements than other groups on several days of testing (see Figure 2). Newman-Keuls post hoc tests indicated that the $20-\mathrm{mg}$ females received significantly $(p<.05)$ fewer reinforcements than did uninjected controls on Days 7, 9, 10, 12, 15 , and 16. An analysis of males alone revealed smaller dose-related differences than those seen in females; these differences did not reach significance. DRL effects in females were not attributable to differences in response rate. No significant dose-related differences were found in response rate.

\section{DISCUSSION}

Daily cocaine administration during the PPA period produced changes in behavior that were detectable about 6 months later. Cocaine effects included a reduction in reinforcements received in a difficult operant barpressing task and altered sensitivity to the motor activity effects of cocaine. Changes were seen at a dose of cocaine that resulted in minor, but significant, body weight reductions in males during the dosing period, but the observed behavioral effects were seen only in females, which had no significant cocaine-related changes in body weight.

Cocaine effects were seen in behaviors previously found to be disrupted by cocaine administration earlier in development. Prenatal cocaine alters cocaine-stimulated activity (see, e.g., Kunko, Wallace, \& Robinson, 1996; Peris, Coleman-Hardee, \& Millard, 1992), and alters DRL performance (Medici, Smith, \& Raap, 1999; Smith et al., 1989; Smith, unpublished data). Thus, two behaviors sensitive to prenatal cocaine exposure continue to be sensitive to cocaine exposure much later in development.

As an initial report, the present study utilized several behavioral tests in the same animals. Since each animal was tested on each task, it is not possible to distinguish whether, for example, juvenile cocaine directly alters DRL performance or whether the observed differences on DRL are attributable to an interaction of juvenile dosing and the testing experiences in the open field. It is also

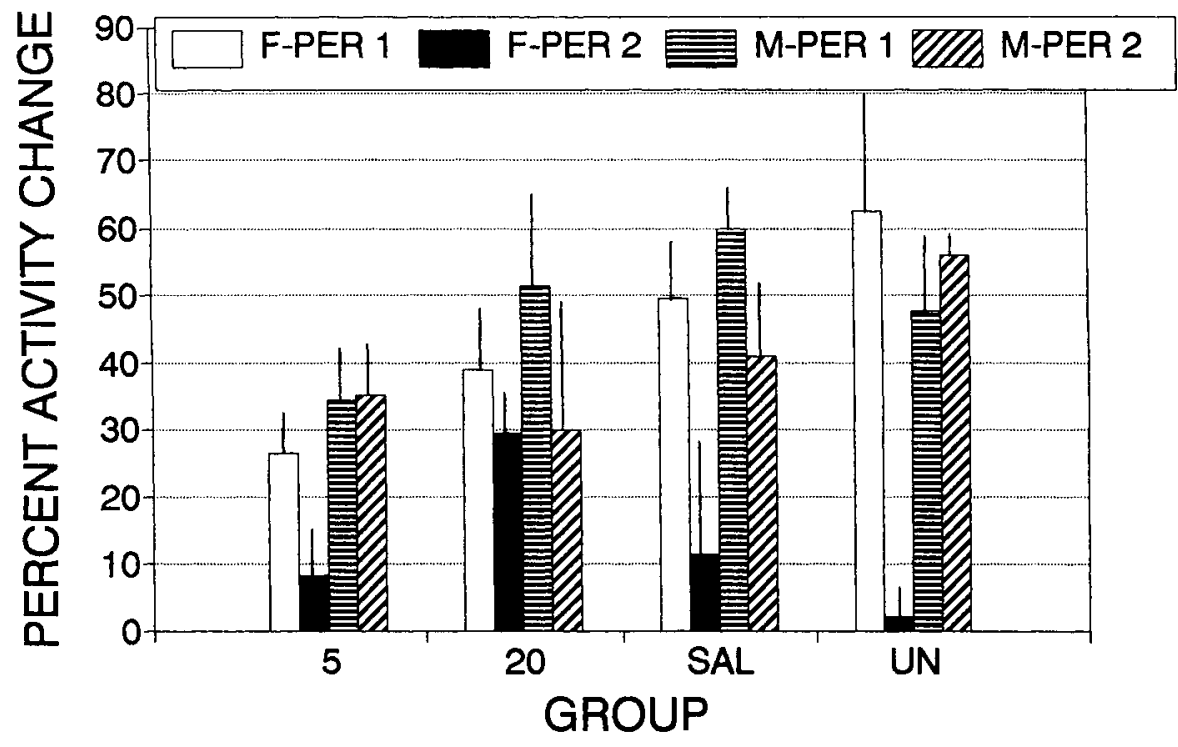

Figure 1. Cocaine-induced changes in activity in the open field. Data points represent percent change from basal (nondrugged) activity. Only two consecutive 5-min time periods were tested after $5-\mathrm{mg} / \mathrm{kg}$ cocaine injection, and those are compared with the first two 5 -min periods of basal activity data. $N=5$ /group. F-PER 1, female, time period 1; F-PER 2, female, time period 2; MPER 1, male, time period 1; M-PER 2, male, time period 2; SAL, saline-injected; UN, uninjected. 


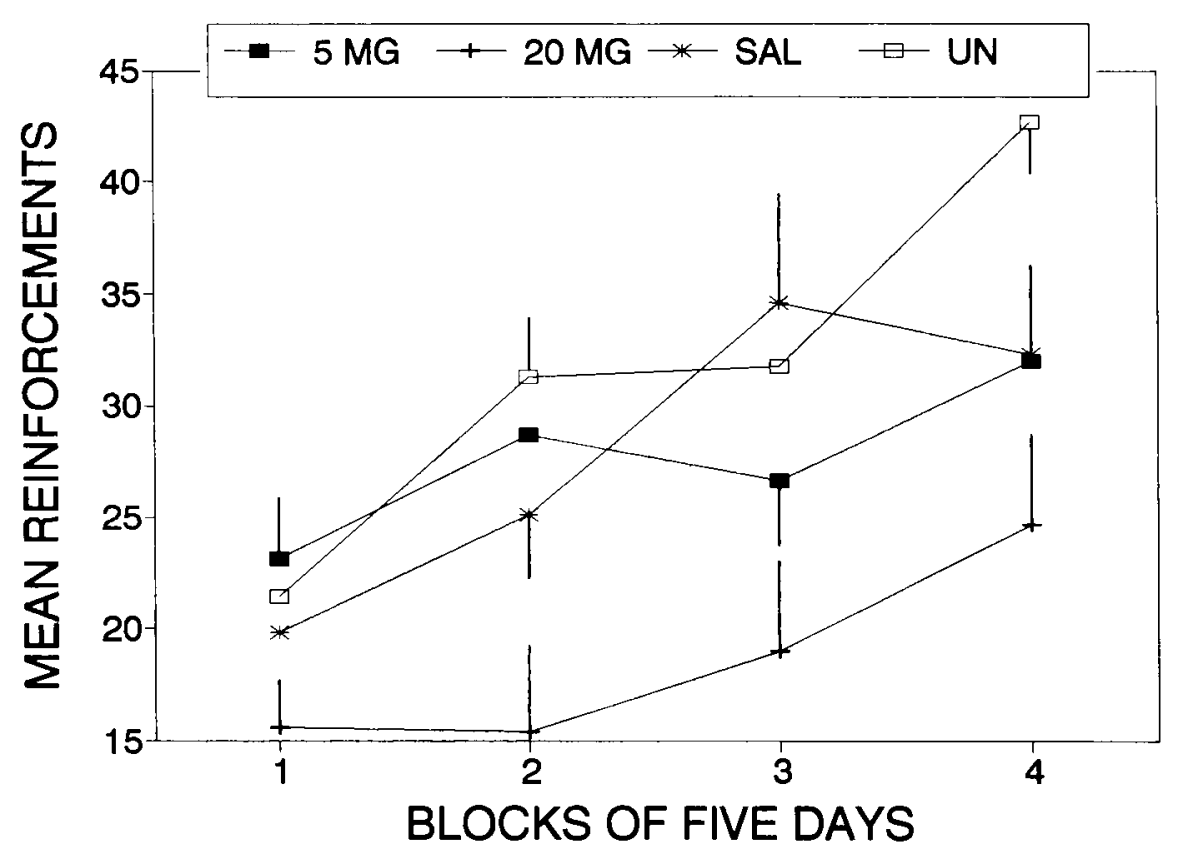

Figure 2. Differential reinforcement of low rates of responding for females. Data are averaged across 5-day blocks for clarity. $N=5$ /group.

possible that DRL carries over to cocaine-stimulated activity. At one level of analysis, this distinction lacks meaning, since our data indicate to an effect of cocaine; however, it is clearly of importance to determine whether cocaine directly affects substrates for a behavior or whether it affects how those substrates may be altered by experiences intervening between dosing and testing. We note that several reports have indicated that earlier (prenatal) cocaine administration may alter reactions to environmental events and, subsequently, alter behavior (Smith et al., 1989; Wood, Molina, Wagner, \& Spear, 1995).

The present data suggest that PPA cocaine produced very long lasting changes in the CNS. Clearly, effects detected approximately 6 months after the end of cocaine administration cannot be attributed to residual cocaine. Although the developing CNS is subject to environmentally-induced structural changes at the ages at which administration occurred (Greenough, 1987; Juraska, Fitch, Henderson, \& Rivers, 1985), there have been few studies of whether drug exposure at these ages produce lasting effects on behavior. We have found that PPA cocaine also produces lasting alterations in estrous cyclicity (Raap, Smith, \& Medici, 1996) and in cocaine place preference (Smith, Morin, Raap, \& Medici, 1996). Other studies of juvenile drug effects are beginning to emerge; Harrison, Connor, Nowak, and Melloni (1997) reported that chronic juvenile cocaine enhances intruder aggression in hamsters, tested shortly after administration ceased. Melloni, Connor, Nash, and Harrison (1997) also found that juvenile androgen increases aggression and hypothalamic arginine vasopressin in hamsters; as with the Harrison study, this effect was examined shortly after the conclusion of drug administration. Shtiegman, King, and Ferris (1997) found a similar effect on aggression after juvenile alcohol. Siciliano, Smith, and Morin (1997) found that chronic alcohol during the PPA period produced later changes on DRL and the open field.

The mechanisms by which PPA drug exposure might produce long-lasting changes in behavior are poorly understood. We note, however, that increased excitatory neurotransmitter activity stimulates process outgrowth in neurons (Lipton \& Kater, 1989). Enrichment effects on brain growth may be maximal in areas undergoing active growth at the time of enrichment (Fernandez et al., 1997). We hypothesize that synaptic activity stimulated by PPA cocaine may induce lasting neuromorphological changes, much as stimulation-induced activity appears to. Subsequently, these morphological changes may mediate lasting changes in behavior. However, possible similarities between mechanisms underlying enrichment and cocaine probably do not imply similar behavioral effects of the two; the stimulation produced by enrichment most affects particular sensory system(s) subject to stimulation, whereas the cocaine effects most affect particular neurotransmitter systems.

The analogy to the environmental enrichment literature offers a possible explanation for the gender-specific effects noted in the present study. Juraska et al. (1985) found that dendritic branching in response to enrichment is gender-specific, with female (i.e., nontestosteroneprimed) CNS being less reactive to enrichment than is male (i.e., primed) CNS. Dow-Edwards et al. (1993) found a similar female-limited effect for cocaine dosing in the P11-P20 period; as measured later at P63, cocaine 
dosing altered metabolic rates (2-DG uptake) only in females. Interestingly, we further analyzed Dow-Edwards et al.'s (1993) data and found that most cocaine effects in females were in brain areas with sexually differentiated metabolic rates and that cocaine shifted rates toward the male-typical values (unpublished; available from the authors by request). Thus, either developmental cocaine or environmental enrichment can interact with gender to affect aspects of CNS structure or function. An underlying mechanism for the gender differentiation in putative cocaine-induced CNS changes may be that neurons in females have greater morphological (growth) responses to cocaine-stimulated firing.

Endocrine disruption may also play a role in the effects of PPA cocaine. Although we did not measure steroid levels, cocaine in older rats produces multiple endocrine effects (King, Schenken, Kang, Javors, \& Riehl, 1990). The male-limited body weight suppression we observed during administration may have been due to cocaineinduced reduction in testosterone and its subsequent anabolic effects (Li, George, Bianco, Lawrence, \& Dhabuwala, 1997). Raap et al. (1996) also found that PPA cocaine disrupts estrous cyclicity in females (both during and following dosing), likely reflecting underlying cocaineinduced hormonal effects. Further work will be required to determine whether disruption of endocrine control systems underlies the effects of PPA cocaine.

Although only 5 sex pairs of animals were tested per drug condition, PPA cocaine resulted in significant changes in behavior. Significance with these group sizes may be partly due to the sensitivity of the experimental design; since the design matched subjects for genetic and litter factors across dose groups, those components of variance did not contribute to the error variance. This resulted in relatively high power for a small subject size for detecting interactions, ranging from .724 for the triple interaction in cocaine-stimulated versus basal open field activity to 1.000 for the triple interaction in DRL reinforcements; power for group and sex main effects was much lower, in some cases less than .2. When its use is feasible, this design appears to be sensitive to interaction effects with relatively small sample sizes. Clearly, however, the results reported here require replication with larger sample sizes.

The present study included a restricted range of behavioral tests, but the effects warrant some concern. Our data on basal versus cocaine-stimulated open field activity imply that PPA cocaine may cause long-lasting changes in sensitivity to cocaine; if verified, this might affect later predisposition to self-administer cocaine. The DRL task is a relatively difficult operant task, and our changes in female performance on this task suggest that the neural systems mediating this type of cognitive learning may be altered by PPA cocaine, which suggests that similar types of cognitive learning may be altered by this dosing regimen.

Clearly, drug use of many types is detrimental to neural development when administration occurs during pre- natal development, in both animals and humans. The present data contribute to a recent small body of data suggesting that the sensitivity of the developing CNS to drug-induced alterations continues into the approximate period of middle childhood through puberty. Since human use of addictive drugs is high during the PPA period, these data underscore the need to better understand the consequences of PPA cocaine.

\section{REFERENCES}

Akbari, H. M., Kramer, J. K., Whitaker-Azmitia, P. M., Spear, L. P., \& Azmitia, E. C. (1992). Prenatal cocaine exposure disrupts the development of the serotonergic system. Brain Research, 572, 57-63.

Barron, S., \& IRVINE, J. (1994). Effects of neonatal cocaine exposure on two measures of balance and coordination. Neurotoxicology $\&$ Teratology, 16, 89.94.

Chasnoff, I. J., Burns, W. J., Schnoll, S. H., \& Burns, K. A. (1985). Cocaine use in pregnancy. New England Journal of Medicine, 313, 666-669.

Dow-Edwards, D. L., Fried, L. A., \& Fico, T. A. (1990). Structural and functional effects of prenatal cocaine exposure in adult rat brain. Developmental Brain Research, 57, 263-268.

Dow-Edwards, D. E., Fried-Malen, L. A., \& Hughes, H. E. (1993). Long-term alterations in brain function following cocaine administration during the preweanling period. Developmental Brain Research, 72, 309-313.

Driscoll, C. D., Streissguth, A. P., \& Riley, E. P. (1990). Prenatal alcohol effects: Comparability of effects in humans and animal models. Neurotoxicology \& Teratology, 12, 231-237

Fernandez, V., Adaro, L., Sanhueza-Tsusumi, M., Inzunza, O., \& Bravo, H. (1997). Early-life polysensorial stimulation and nutrition: Topographic levels of susceptibility in the rat visual cortex. Biology of the Neonate, 71, 265-276.

Goodwin, G. A., Moody, C. A., \& Spear, L. P. (1993). Prenatal cocaine exposure increases the behavioral sensitivity of neonatal rat peps to ligands active at opiate receptors. Neurotoxicology \& Teratology, 15, 425-431.

Greenough, W. T. (1987). Experience effects on the developing and the mature brain: Dendritic branching and synaptogenesis. In N. A. Krasnegor, E. M. Blass, M. A. Hofer, \& W. P. Smotherman (Eds.), Perinatal development: A psychobiological perspective (pp. 195221). New York: Academic Press.

Harrison, R. J., Connor, D. F., Nowak, C., \& Melloni, R. H. (1997). Chronic cocaine treatment during adolescence stimulates offensive aggression in golden hamsters. Society for Neuroscience Abstracts, 23, 1094.

Heyser, C. J., Chen, W.-J., Miller, J., Spear, N. E., \& Spear, L. P. (1990). Prenatal cocaine exposure induces deficits in Pavlovian conditioning and sensory preconditioning among infant rat pups. Behavioral Neuroscience, 104, 955-963.

Hicks, J. M., Morales, A., \& Soldin, S. J. (1990). Drugs of abuse in a pediatric outpatient population. Clinical Chemistry, 36, 1256-1257.

Johns, J. M., Means, M. J., Anderson, D. R., Means, L. W., \& McMillen, B. A. (1992). Prenatal exposure to cocaine. 11: Effects on open-field activity and cognitive behavior in Sprague--Dawley rats. Neurotoxicology \& Teratology, 14, 343-349.

Juraska, J. M., Fitch, J. M., Henderson, C., \& Rivers, N. (1985). Sex differences in the dendritic branching of dentate granule cells following differential experience. Brain Research, 333, 119-127.

Kaltenbach, K. A., \& Finnegan, L. P. (1989). Prenatal narcotic exposure: Perinatal and developmental effects. Neurotoxicology, 10, 597-604.

King, T. S., Schenken, R. S., Kang, I. S., JavorS, M. A., \& Riehl, R. M. (1990). Cocaine disrupts estrous cyclicity and alters the reproductive neuroendocrine axis in rats. Neuroendocrinology, 51, 15-22.

KIRK, R. E. (1982). Experimental design: Procedures for the behavioral sciences. Pacific Grove, CA: Brooks/Cole.

Kunko, P. M., Wallace, M. J., \& Robinson, S. E. (1996). Gestational 
cocaine and alcohol exposure alter spontaneous and cocaine-induced behavior in weanling rats. Pharmacology, Biochemistry \& Behavior, $55,559-564$.

Li, H., George, V. K., Bianco, F. J., Lawrence, W. D., \& Dhabuwala, C. B. (1997). Histopathological changes in the testes of prepubertal male rats after chronic administration of cocaine. Journal of Environmental Pathology, Toxicology, \& Oncology, 16, 67-71.

LipTON, S. A., \& KaTER, S. B. (1989). Neurotransmitter regulation of neuronal outgrowth, plasticity and survival. Trends in Neurosciences, $12,265-270$.

Medici, C. N., Smith, R. F., \& RAAP, D. K. (1999). Behavioral effects of prenatal cocaine are not selectively modified by postweaning environmental enrichment. Manuscript in preparation.

Melloni, R. H., Jr., Connor, D. F., Nash, K., \& Harrison, R. J. (1997). Chronic anabolic steroid exposure during adolescence stimulates vasopressin-dependent aggression in hamsters. Society for Neuroscience Abstracts, 23, 1870.

Morgan, M. (1973). Effects of post-weaning environment on learning in the rat. Animal Behavior, 21, 429-442.

Ough, B. R., Beatty, W. W., \& Khalili, J. (1972). Effects of isolated and enriched rearing on response inhibition. Psychonomic Science, 27, 293-294.

Peris, J., Coleman-Hardee, M., \& Millard, W. J. (1992). Cocaine in utero enhances the behavioral response to cocaine in adult rats. Pharmacology, Biochemistry \& Behavior, 42, 509-515.

RaAP, D. K., Smith, R. F., \& Medici, C. N. (1996). Periadolescent cocaine and stress effects on reproductive maturation and estrous cyclicity in the female rat. Society for Neuroscience Abstracts, 2, 1884.

Raum, W. J., McGivern, R. F., Peterson, M. A., Shryne, J. H., \& GorSKI, R. A. (1990). Prenatal inhibition of hypothalamic sex steroid uptake by cocaine: Effects on neurobehavioral sexual differentiation in male rats. Developmental Brain Research, 53, 230-236.

Shtiegman, K., King, J. A., \& Ferris, C. (1997). Voluntary alcohol consumption during adolescence in golden hamsters elevates blood testosterone and increases aggression during early adulthood. Society for Neuroscience Abstracts, 23, 1863.

Siciliano, D., Smith, R. F., \& Morin, L. (1997). Juvenile alcohol consumption in the rat induces behavioral changes evident later in adulthood. Society for Neuroscience Abstracts, 23, 1864.
Smith, R. F., Mattran, K. M., Kurkjian, M. F., \& Kurtz, S. L. (1989). Alterations in offspring behavior induced by chronic prenatal cocaine dosing. Neurotoxicology \& Teratology, 11, 35-38.

Smith, R. F., Morin, L., RaAP, D. K., \& Medici, C. N. (1996, November). Context-specific enhancement of cocaine conditioned place preference in pre-/peri-adolescent cocaine exposure. Paper presented at the annual meeting of the International Society for Developmental Psychobiology, Washington, D.C.

Smith, R. F., Royall, G. D., \& Coss, M. (1995). Prenatal cocaine produces dose-dependent suppression of prolactin and growth hormone in neonatal rats. Physiology \& Behavior, 58, 619-623.

Spear, L. P., Kirstein, C. L., \& Frambes, N. A. (1989). Cocaine effects on the developing central nervous system: Behavioral, psychopharmacological, and neurochemical studies. In D. E. Hutchings (Ed.), Prenatal abuse of licit and illicit drugs (Annals of the New York Academy of Sciences, Vol. 562, pp. 290-307) New York: New York Academy of Sciences.

SPencer, D. G., JR., \& Emmett-Oglesby, M. W. (1985). Parallel processing strategies in the application of microcomputers to the behavioral laboratory. Behavior Research Methods, Instruments, \& Computers, 17, 294-300.

U.S. Department of Health \& Human Services (1991). National Household Survey on Drug Abuse: Highlights 1990 (DHHS Publication No. [ADM] 1789-91). Washington, DC: Author.

VATHY, I., KaTAY, L., \& MINI, K. N. (1993). Sexually dimorphic effects of prenatal cocaine on adult sexual behavior and brain catecholamines in rats. Developmental Brain Research, 73, 115-122.

WinER, B. J. (1971). Statistical principles in experimental design. New York: McGraw-Hill

WITT, E. D. (1994). Mechanisms of alcohol abuse and alcoholism in adolescents: A case for developing animal models. Behavioral \& Neural Biology, 62, 168-177.

Wood, R. D., Molina, V. A., Wagner, J. M., \& Spear, L. P. (1995). Play behavior and stress responsivity in periadolescent offspring exposed prenatally to cocaine. Pharmacology, Biochemistry \& Behavior, 52, 367-374.

(Manuscript received January 21, 1997; revision accepted for publication January 25,1999 .) 